\title{
PORTA-ENXERTOS PARA LARANJEIRAS-DOCES (CITRUS SINENSIS (L.) OSB.), EM RIO BRANCO, ACRE 1
}

\author{
ANA DA SILVA LEDO², FRANCISCO JOSÉ DA SILVA LEDO², ROGÉRIO RITZINGER ${ }^{3}$ \\ e ALMIR PINTO DA CUNHA SOBRINHO
}

\begin{abstract}
RESUMO - O objetivo deste trabalho foi de avaliar o comportamento de sete cultivares de laranjeirasdoces: 'Baia 101', 'Baianinha IAC 79', 'Monte Parnaso', 'Pêra D6', 'Natal 112', 'Valência 27' e 'Aquiri', sobre diferentes porta-enxertos: limão 'Cravo', tangerinas 'Cleópatra' e 'Sunki' e citrange 'Carrizo', nas condições edafoclimáticas de Rio Branco, Acre. O delineamento experimental foi em parcelas subdivididas, com as cultivares nas parcelas, os porta-enxertos nas subparcelas e os quatro anos de avaliação como repetições. As laranjeiras 'Pêra D6', 'Natal 112' e 'Valência 27' apresentaram tendências de maior produção quando enxertadas sobre o limão 'Cravo', e a laranja 'Aquiri' quando enxertada sobre citrange 'Carrizo'. Em relação aos demais porta-enxertos, o limão 'Cravo' mostrou tendências de induzir maior produção/volume de copa e peso médio do fruto, e menor teor de sólidos solúveis totais e acidez total. As laranjas do grupo Baia ('Baia 101', 'Baianinha IAC 79' e 'Monte Parnaso') produziram frutos com baixa percentagem de suco; não são recomendadas para plantio em Rio Branco, AC. Com base nos resultados obtidos, recomendam-se os porta-enxertos citrange 'Carrizo', tangerina 'Cleópatra' e limão 'Cravo' para a laranja 'Aquiri', e o porta-enxerto limão 'Cravo' para as laranjas 'Pêra D6', 'Natal 112' e 'Valência 27'.
\end{abstract}

Termos para indexação: Amazônia, produção de laranja, qualidade do fruto.

\section{ROOTSTOCKS FOR SWEET ORANGE (CITRUS SINENSIS (L.) OSB.) IN RIO BRANCO, ACRE, BRAZIL}

\begin{abstract}
The objective of this study was to evaluate the behaviour of seven sweet orange cultivars: 'Baia 101', 'Baianinha IAC 79', 'Monte Parnaso', 'Pêra D6', 'Natal 112', 'Valência 27' and 'Aquiri' grafted on different rootstocks: 'Rangpur' lime, 'Cleópatra' and 'Sunki' mandarins, and 'Carrizo' citrange, in the environmental conditions of Rio Branco, Acre, Brazil. The experimental design was a split-plot, with the sweet orange cultivars as the main plots, the rootstocks as the subplots, and the four years of evaluation as replications. The 'Pêra D6', 'Natal 112' and 'Valência 27' sweet orange cultivars tended to have the highest yield when grafted on 'Rangpur' lime rootstocks, and the 'Aquiri' orange when grafted on 'Carrizo' citrange. Compared to the other rootstocks used, the 'Rangpur' lime tended to induce the highest yield/canopy volume and highest mean fruit weight, and the lowest total soluble solids and total acidity. Sweet orange cultivars of the 'Baia' group ('Baia 101', 'Baianinha IAC 79' and 'Monte Parnaso') produced fruit with low juice content, therefore they are not recommended for planting in Rio Branco. Based on the results, the rootstocks 'Carrizo' citrange, 'Cleópatra' mandarin and 'Rangpur' lime are recommended for 'Aquiri' sweet orange, and the 'Rangpur' lime is recommended for 'Pêra D6', 'Natal 112' and 'Valência 27' sweet orange cultivars.
\end{abstract}

Index terms: Amazon, sweet orange yield, fruit quality.

\footnotetext{
${ }^{1}$ Aceito para publicação em 9 de outubro de 1998.

${ }^{2}$ Eng. Agr., M.Sc., Embrapa-Centro de Pesquisa Agroflorestal do Acre (CPAF-Acre), Caixa Postal 392, CEP 69908-150 Rio Branco, AC. E-mail: analedo@ultranet.com.br

${ }^{3}$ Eng. Agr., Ph.D., Embrapa-CPAF-Acre.

${ }^{4}$ Eng. Agr., M.Sc., Embrapa-Centro Nacional de Pesquisa de Mandioca e Fruticultura Tropical (CNPMF), Caixa Postal 007, CEP 44380-000 Cruz das Almas, BA.
}

\section{INTRODUÇ̃̃̃O}

O Brasil é o maior produtor mundial de frutas cítricas, especialmente laranjas, e é também o maior produtor e exportador de suco concentrado congelado. Em 1994, a produção brasileira de laranja atingiu 18,6 milhões de toneladas e a de suco concentrado 984 mil litros, que corresponderam a $31,7 \%$ e 
$46,5 \%$, respectivamente, do total mundial (Neves, 1996). A área plantada e a produção de laranja no Estado do Acre é de, respectivamente, 120 ha e 12.349 t/ha (Anuário Estatístico do Brasil, 1994). Grande parte do volume de frutos cítricos comercializados na região é importada do Estado de São Paulo.

Apesar de haver condições para o cultivo de laranja no Acre, o produtor acreano carece de informações sobre o comportamento produtivo e de qualidade de fruto das diversas cultivares no Estado. A inexistência dessas informações, o uso de cultivares que não se adaptam bem às condições edafoclimáticas do Acre, a utilização de um único portaenxerto e a comercialização de mudas de baixa qualidade constituem fatores limitantes para o desenvolvimento local da citricultura (Ritzinger et al., 1992).

No Estado do Acre, o porta-enxerto limão 'Cravo' é muito utilizado, dadas as suas características de vigor, produtividade, tolerância ao vírusda-tristeza, compatibilidade com diferentes copas cítricas e resistência à seca (Pompeu Júnior, 1980). A predominância deste porta-enxerto causa preocupação, por ser susceptível à gomose (Phytophthora spp.), cuja incidência é alta no Estado, e ao declínio, que vem se manifestando nas regiões produtoras do Estado de São Paulo (Beretta et al., 1986; Castle et al., 1993). Sabendo-se da existência de porta-enxertos que apresentam maior tolerância a estas doenças (Koller \& Soprano, 1992; Koller, 1994), a diversificação de porta-enxertos poderá contribuir na longevidade e no aumento da produtividade de plantios de citros na Amazônia Ocidental.

O objetivo do trabalho é avaliar o comportamento de cultivares de laranja-doce enxertadas sobre quatro porta-enxertos, nas condições edafoclimáticas de Rio Branco, Acre.

\section{MATERIAL E MÉTODOS}

O experimento foi instalado em fevereiro de 1989 , no Campo Experimental da Embrapa-Centro de Pesquisa Agroflorestal do Acre (Embrapa-CPAF-Acre), em Rio Branco, AC, em uma área anteriormente coberta por floresta primária. O solo foi classificado como Podzólico Vermelho-Amarelo, de fertilidade média, com baixos te- ores de $\mathrm{Al}\left(\mathrm{Al}=20,00 \mathrm{mmol}_{\mathrm{c}} / \mathrm{dm}^{3}\right)$, acidez média $(\mathrm{pH}=5,3)$, teores médios de $\mathrm{Ca}$ e $\mathrm{Mg}(\mathrm{Ca}+$ $\left.\mathrm{Mg}=36,00 \mathrm{mmol}_{\mathrm{c}} / \mathrm{dm}^{3}\right)$, baixo teor de $\mathrm{P}(\mathrm{P}=5 \mathrm{mg} / \mathrm{kg})$ e alto teor de $\mathrm{K}(\mathrm{K}=80 \mathrm{mg} / \mathrm{kg})$.

O clima da região é quente e úmido com estações seca e chuvosa bem definidas (Awi). A temperatura média anual é de $25,1^{\circ} \mathrm{C}$, sendo a média das máximas de $31,2^{\circ} \mathrm{C}$, e a média das mínimas de $20^{\circ} \mathrm{C}$. As médias anuais de precipitação, umidade relativa do ar e insolação são $1.889,7 \mathrm{~mm}, 84 \%$ e $1.748,5$ horas, respectivamente (Embrapa, 1990).

Sete cultivares de laranjas-doces (Citrus sinensis (L.) Osb.) foram avaliadas: Baia 101, Baianinha IAC 79, Monte Parnaso, Pêra D6, Natal 112, Valência 27 e Aquiri (seleção local), enxertadas sobre quatro porta-enxertos: limão 'Cravo' (Citrus limonia Osb.), tangerinas 'Sunki' (Citrus sunki Hort. ex Tan.) e 'Cleópatra' (Citrus reshni ex Hort. Tan.), e citrange 'Carrizo' (Citrus sinensis (L.) Osb. x Poncirus trifoliata Raf.). A cultivar de laranja-doce Aquiri, também conhecida como Murilosa, foi obtida a partir da seleção de materiais locais no município de Rio Branco, Acre, apresentando árvores de porte médio a alto, com frutos esféricos, suculentos, de tamanho médio, polpa alaranjada, textura firme, com oito a dez sementes, casca de espessura média e cor verde-amarelada. A época de produção concentra-se no período de abril a junho.

As mudas foram produzidas na Embrapa-CPAF-Acre, com borbulhas oriundas da Embrapa-Centro Nacional de Pesquisa de Mandioca e Fruticultura Tropical. Cada combinação cultivar/porta-enxerto foi representada por três plantas, com espaços, entre si, de 8,0 x 8,0 m. O delineamento experimental foi o de blocos casualizados, em parcelas subdivididas, com as cultivares nas parcelas e os porta-enxertos nas subparcelas, com bordadura externa. Como repetição foram considerados quatro anos de avaliação (quarto ao sétimo ano de produção).

A adubação de manutenção e os demais tratos culturais foram aplicados de acordo com as recomendações de Cunha Sobrinho et al. (1985). Foram obtidos dados de: altura da planta (m) e diâmetro da copa (m), utilizados para o cálculo do volume médio da copa $\left(\mathrm{m}^{3}\right)$, produção média por planta (kg/planta), produção média por volume de copa $\left(\mathrm{kg} / \mathrm{m}^{3}\right)$, e peso médio do fruto $(\mathrm{g})$. O volume da copa (V) foi determinado com base na fórmula: $V=2 / 3 \pi R^{2} H$, em que $R=$ raio médio da copa e $H=$ altura da planta. A qualidade química dos frutos foi determinada pela avaliação da porcentagem em peso de suco (\%), acidez total titulável (ATT), teor de sólidos solúveis (TSS) e relação TSS/ATT. As determinações foram efetuadas em três amostras de dez frutos de cada combinação copa/porta-enxerto do quarto ao sétimo ano de idade. A 
porcentagem em peso de suco foi calculada pela diferença entre o peso total dos frutos e o peso do bagaço (casca, sementes e demais fragmentos retidos em uma peneira fina de 100 malhas $/ \mathrm{cm}^{2}$ ). O teor de sólidos solúveis (TSS) foi lido em um refratômetro de mão e posteriormente foi corrigido em função da temperatura ambiente, e a acidez total titulável foi obtida pela titulação de $25 \mathrm{~mL}$ de suco com uma solução-padrão de hidróxido de sódio $0,1 \mathrm{~N}$, usando-se fenolfetaleína como indicador (Pio et al., 1993). Os dados foram submetidos à análise de variância pelo teste $\mathrm{F}$, e, quando constatada significância estatística, foi feita a comparação das médias pelo teste de Tukey.

\section{RESULTADOS E DISCUSSÃO}

Para efeito da análise estatística não foram consideradas as cultivares de laranja do grupo Baia ('Baia 101', 'Baianinha IAC 79' e 'Monte Parnaso'), por causa da não-adaptação às condições edafoclimáticas de Rio Branco, Acre. Estas cultivares, ao longo de quatro anos de produção, apresentaram frutos com baixo rendimento de suco nos quatro porta-enxertos em estudo, inviabilizando as análises de características físico-químicas dos frutos.

Conforme os resultados da análise de variância (Tabela 1), referentes ao volume médio da copa e produção média por planta, houve efeito significativo da interação cultivar x porta-enxerto. A laranja
'Aquiri' apresentou tendência de maior volume médio de copa, dentro de cada porta-enxerto, destacando-se, neste aspecto, os porta-enxertos limão 'Cravo', tangerina 'Cleópatra' e citrange 'Carrizo'. A tangerina 'Sunki' proporcionou redução significativa no volume médio da copa quando usada como porta-enxerto nas combinações com as laranjas 'Aquiri' e 'Valência 27' (Tabela 2); houve, também, tendência de redução na produção média por planta, nestas duas combinações (Tabela 3). A laranja 'Natal 112' apresentou maior produção média por planta quando enxertada sobre o limão 'Cravo' $(160,5 \mathrm{~kg} / \mathrm{pl})$, diferindo significativamente dos demais porta-enxertos utilizados. As laranjas 'Valência 27' e 'Pêra D6' também mostraram tendências de maior produção sobre o limão 'Cravo'. Embora não houvesse significância estatística em relação à produção média por planta entre os portaenxertos utilizados com a laranja 'Aquiri', observou-se tendência de maior produção desta laranja quando enxertada sobre citrange 'Carrizo' (140,5 kg/pl), seguido pela tangerina 'Cleópatra' e limão 'Cravo' (122,9 e 116,4 kg/pl, respectivamente) (Tabela 3).

Não houve efeito significativo da interação cultivar $\mathrm{x}$ porta-enxerto sobre a produção média por volume de copa, peso médio do fruto, teor de sóli-

TABELA 1. Análise de variância do volume médio da copa (VMC), produção média por planta (PMP), produção média por volume de copa (PMV) e peso médio do fruto (PMF) de cultivares de laranja enxertadas sobre quatro porta-enxertos, do $4^{\circ}$ ao $7^{\circ}$ ano de idade, em Rio Branco, AC.

\begin{tabular}{|c|c|c|c|c|c|}
\hline \multirow[t]{2}{*}{ Fonte de variação } & \multirow[t]{2}{*}{ G.L. } & \multicolumn{4}{|c|}{ Quadrados médios } \\
\hline & & VMC & PMP & PMV & PMF \\
\hline Anos & 3 & 2875,99 & 2816,16 & 8,66 & 14909,82 \\
\hline Cultivar (C) & 3 & $2824,11 * *$ & $9122,66^{\mathrm{ns}}$ & $3,76^{\mathrm{ns}}$ & $4122,37^{\mathrm{ns}}$ \\
\hline Resíduo (a) & 9 & 187,71 & 5995,61 & 2,89 & 1582,78 \\
\hline Porta-enxerto (PE) & 3 & $672,39 * *$ & $9733,55^{* *}$ & $3,67^{\mathrm{ns}}$ & $2466,54 * *$ \\
\hline Interação C X PE & 9 & $95,73 * *$ & $2101,68^{*}$ & $1,76^{\mathrm{ns}}$ & $199,03^{\mathrm{ns}}$ \\
\hline Resíduo (b) & 36 & 26,30 & 951,18 & 1,26 & 541,28 \\
\hline $\mathrm{CV}_{\mathrm{a}}(\%)$ & & 42,72 & 84,69 & 58,22 & 19,58 \\
\hline $\mathrm{CV}_{\mathrm{b}}(\%)$ & & 15,99 & 33,73 & 38,48 & 11,45 \\
\hline
\end{tabular}

ns, * e ** Não-significativo e significativo a $5 \%$ e $1 \%$ de probabilidade, respectivamente, pelo teste $\mathrm{F}$. 
dos solúveis (TSS), acidez total titulável (ATT) e relação TSS/ATT. Foi verificado o efeito significativo do porta-enxerto sobre o peso médio do fruto, teor de sólidos solúveis e acidez total, e das cultivares sobre o teor de sólidos solúveis totais (Tabelas 1 e 4). No entanto, a laranja 'Natal 112' apresentou tendência de maior produção por volume de copa em relação às demais laranjas testadas, e a laranja 'Aquiri' de maior peso médio de fruto (Tabela 5). A porcentagem de suco foi alta em todas as combinações de laranja x porta-enxerto, acima de 40\%, o que está de acordo com as observações de Bastos et al. (1981) que, nas condições climáticas de Manaus, AM, obtiveram 48,5\% de rendimento em suco em frutos de laranja 'Pêra'. Cunha Sobrinho et al. (1992) também observaram que frutos produzidos em clima quente e úmido são mais suculentos. O teor de sólidos solúveis totais foi significativamente maior na laranja 'Valência' em relação às de- mais, independentemente do porta-enxerto (Tabela 5).

Os porta-enxertos citrange 'Carrizo' e as tangerinas 'Sunki e 'Cleópatra' promoveram a produção de frutos com maior teor de sólidos solúveis totais e acidez total, em comparação com os frutos produzidos sobre limão 'Cravo' (Tabela 6). Entretanto, este porta-enxerto mostrou que tende a induzir maior produção por volume de copa e peso médio dos frutos nas cultivares de laranja testadas em Rio Branco, AC. A relação Brix/acidez indica o ponto de maturação e de colheita dos frutos, característica importante nas cultivares cítricas (Pio et al., 1993). Segundo Samson, citado por Koller (1994), a relação Brix/acidez ideal seria entre 10 e 16. Conforme os resultados obtidos (Tabela 6), as cultivares de laranja atingiram valores adequados para o consumo in natura (mínimo de 8,0) e para a industrialização (mínimo de 10), o que confere com os padrões citados por Campos (1976).

TABELA 2. Volume médio da copa $\left(\mathrm{m}^{3}\right)$ de cultivares de laranja enxertadas sobre quatro porta-enxertos, do $4^{0}$ ao $7^{0}$ ano de idade em Rio Branco, $\mathrm{AC}^{\mathbf{1}}$.

\begin{tabular}{lllll}
\hline \multirow{2}{*}{ Porta-enxerto } & \multicolumn{4}{c}{ Cultivares } \\
\cline { 2 - 5 } & Aquiri & Pêra D6 & Natal 112 & Valência 27 \\
\hline Limão Cravo & $57,4 \mathrm{aA}$ & $26,2 \mathrm{aB}$ & $32,8 \mathrm{aB}$ & $41,0 \mathrm{aAB}$ \\
Tang. Sunki & $34,5 \mathrm{bA}$ & $17,4 \mathrm{aB}$ & $23,0 \mathrm{aAB}$ & $20,2 \mathrm{cAB}$ \\
Tang. Cleópatra & $55,7 \mathrm{aA}$ & $22,2 \mathrm{aB}$ & $23,9 \mathrm{aB}$ & $33,5 \mathrm{abB}$ \\
Citrange Carrizo & $56,6 \mathrm{aA}$ & $17,8 \mathrm{aB}$ & $22,5 \mathrm{aB}$ & $28,4 \mathrm{bcB}$ \\
\hline${ }^{1}$ Médias seguidas de letras diferentes, maiúsculas nas linhas e minúsculas nas colunas, diferem significativamente entre si (P $\left.\leq 0,05\right)$ pelo teste de Tukey.
\end{tabular}

TABELA 3. Produção média por planta (kg/planta) de cultivares de laranja enxertadas sobre quatro portaenxertos, do $4^{0}$ ao $7^{0}$ ano de idade em Rio Branco, $\mathrm{AC}^{1}$.

\begin{tabular}{lrlcc}
\hline Porta-enxerto & \multicolumn{3}{c}{ Cultivares } \\
\cline { 2 - 5 } & Aquiri & Pêra D6 & Natal 112 & Valência 27 \\
\hline Limão Cravo & $116,4 \mathrm{aA}$ & $88,3 \mathrm{aA}$ & $160,5 \mathrm{aA}$ & $138,6 \mathrm{aA}$ \\
Tang. Sunki & $88,4 \mathrm{aA}$ & $58,1 \mathrm{aA}$ & $75,1 \mathrm{bA}$ & $50,4 \mathrm{bA}$ \\
Tang. Cleópatra & $122,9 \mathrm{aA}$ & $45,9 \mathrm{aA}$ & $74,2 \mathrm{bA}$ & $87,6 \mathrm{abA}$ \\
Citrange Carrizo & $140,5 \mathrm{aA}$ & $45,2 \mathrm{aB}$ & $76,1 \mathrm{bAB}$ & $94,7 \mathrm{abAB}$ \\
\hline
\end{tabular}

${ }^{1}$ Médias seguidas de letras diferentes, maiúsculas nas linhas e minúsculas nas colunas, diferem significativamente entre si $(\mathrm{P} \leq 0,05)$ pelo teste de Tukey. 
TABELA 4. Análise de variância da percentagem de suco (PS), teor de sólidos solúveis (TSS), acidez total titulável (ATT), relação TSS/ATT (RAT) de cultivares de laranja enxertadas sobre quatro portaenxertos, do 40 ao 70 ano de idade em Rio Branco, $\mathrm{AC}$.

\begin{tabular}{|c|c|c|c|c|c|}
\hline \multirow[t]{2}{*}{ Fonte de variação } & \multirow[t]{2}{*}{ G.L. } & \multicolumn{4}{|c|}{ Quadrados médios } \\
\hline & & PS & TSS & ATT & RAT \\
\hline Anos & 3 & 89,623 & 1,386 & 0,929 & 113,230 \\
\hline Cultivar (C) & 3 & $239,224^{\mathrm{ns}}$ & $22,155^{* *}$ & $0,1875^{\mathrm{ns}}$ & $2,307^{\mathrm{ns}}$ \\
\hline Resíduo (a) & 9 & 74,637 & 1,634 & 0,1764 & 16,957 \\
\hline Porta-enxerto (PE) & 3 & $81,471^{\mathrm{ns}}$ & $2,476^{* *}$ & $0,0605^{* *}$ & $1,270^{\mathrm{ns}}$ \\
\hline Interação C X PE & 9 & $11,084^{\mathrm{ns}}$ & $0,231^{\mathrm{ns}}$ & $0,0194^{\mathrm{ns}}$ & $1,475^{\mathrm{ns}}$ \\
\hline Resíduo (b) & 36 & 31,030 & 0,161 & 0,0135 & 2,0256 \\
\hline $\mathrm{CV}_{\mathrm{a}}(\%)$ & & 17,84 & 13,62 & 42,87 & 39,53 \\
\hline $\mathrm{CV}_{\mathrm{b}}(\%)$ & & 11,50 & 4,28 & 11,90 & 13,66 \\
\hline
\end{tabular}

ns, $* \mathrm{e}^{* *}$ Não-significativo e significativo a $5 \%$ e $1 \%$ de probabilidade, respectivamente, pelo teste $\mathrm{F}$.

TABELA 5. Efeito da cultivar em laranjeiras enxertadas sobre quatro porta-enxertos sobre a produção média por volume de copa e características dos frutos, avaliadas do $4^{0}$ ao $7^{0}$ ano de idade, em Rio Branco, $\mathrm{AC}^{1}$.

\begin{tabular}{|c|c|c|c|c|}
\hline \multirow[t]{2}{*}{ Características } & \multicolumn{4}{|c|}{ Cultivares } \\
\hline & Aquiri & Pêra D6 & Natal 112 & Valência 27 \\
\hline Produção/volume copa $\left(\mathrm{kg} / \mathrm{m}^{3}\right)$ & 2,5 & 2,7 & 3,6 & 2,9 \\
\hline Peso médio do fruto $(\mathrm{g})$ & 227 & 194 & 192 & 199 \\
\hline Suco $(\%)$ & 43,8 & 48,1 & 48,5 & 53,3 \\
\hline Sólidos solúveis totais (Brix) & $8,4 \mathrm{~b}$ & $9,4 b$ & $8,7 b$ & $11,0 \mathrm{a}$ \\
\hline Acidez total $(\mathrm{mL} \mathrm{NaOH} 0,1 \mathrm{~N})^{2}$ & 0,84 & 1,04 & 0,96 & 1,08 \\
\hline Relação Brix/Acidez & 10,8 & 9,9 & 10,4 & 10,6 \\
\hline
\end{tabular}

${ }^{1}$ Médias seguidas de letras diferentes nas linhas diferem significativamente entre si $(\mathrm{P} \leq 0,05)$ pelo teste de Tukey; ausência de letras nas linhas indica que não houve significância estatística.

2 Cada amostra para titulação foi constituída de $25 \mathrm{~mL}$ de suco.

TABELA 6. Efeito do porta-enxerto sobre a produção média por volume de copa e características dos frutos das cultivares de laranja, avaliadas do $4^{0}$ ao $7^{0}$ ano de idade, em Rio Branco, $\mathrm{AC}^{1}$.

\begin{tabular}{lcccc}
\hline \multirow{2}{*}{ Características } & \multicolumn{4}{c}{ Porta-enxertos } \\
\cline { 2 - 5 } & Cravo & Sunki & Cleópatra & Carrizo \\
\hline Produção/volume copa $\left(\mathrm{kg} / \mathrm{m}^{3}\right)$ & 3,6 & 2,9 & 2,5 & 2,8 \\
Peso médio do fruto $(\mathrm{g})$ & $219 \mathrm{a}$ & $201 \mathrm{ab}$ & $189 \mathrm{~b}$ & $204 \mathrm{ab}$ \\
Suco (\%) & 45,8 & 49,6 & 50,8 & 47,4 \\
Sólidos solúveis totais $(B r i x)$ & $8,8 \mathrm{~b}$ & $9,6 \mathrm{a}$ & $9,4 \mathrm{a}$ & $9,7 \mathrm{a}$ \\
Acidez total (mL NaOH 0,1N) & $0,91 \mathrm{~b}$ & $1,05 \mathrm{a}$ & $0,99 \mathrm{ab}$ & $0,97 \mathrm{ab}$ \\
Relação Brix/Acidez & 10,6 & 10,0 & 10,5 & 10,6 \\
\hline${ }^{1}$ Médias seguidas de letras diferentes nas linhas diferem significativamente entre si $(\mathrm{P} \leq 0,05)$ pelo teste de Tukey; ausência de letras nas linhas indica \\
que não houve significância estatística.
\end{tabular}




\section{CONCLUSÕES}

1. As cultivares de laranja Aquiri, Natal 112 e Valência 27 plantadas em Rio Branco, AC, se destacam quanto à produção média de frutos por planta, os quais apresentam boas características comerciais para o consumo in natura no mercado interno, sendo que os frutos da 'Aquiri' e 'Valência' também são adequados para a indústria de suco concentrado.

2. A laranja 'Natal 112' apresenta, em média, um bom rendimento de produção de frutos por $\mathrm{m}^{3} \mathrm{de}$ volume de copa.

3. Recomenda-se o citrange 'Carrizo', o limão 'Cravo' e a tangerina 'Cleópatra' como porta-enxertos para a laranja 'Aquiri', e o limão 'Cravo' para a 'Natal 112' e 'Valência 27'.

4. Não se recomenda o plantio das cultivares de laranja do grupo Baia, dada à sua não-adaptação às condições edafoclimáticas de Rio Branco, Acre.

\section{REFERÊNCIAS}

ANUÁRIO ESTATÍSTICO DO BRASIL, Rio de Janeiro: IBGE, 1994. p.78-96.

BASTOS, J.B.; TEIXEIRA, L.B.; COELHO, Y. da S. Qualidade das laranjas Baia, Pêra e Baianinha em Manaus. Manaus: Embrapa-UEPAE de Manaus, 1981. 4p. (Embrapa-UEPAE de Manaus. Pesquisa em andamento, 24).

BERETTA, M.J.G.; ROSSETTI, V.; TEÓFILO SOBRINHO, J.; POMPEU JÚNIOR, J.; FOGAÇA, M.; JACON, J.R. Incidência do declínio de plantas cítricas em diversos porta-enxertos. In: CONGRESSO BRASILEIRO DE FRUTICULTURA, 8., 1986, Brasília. Anais... Brasília: SBF, 1986. p.237-241.

CAMPOS, J.S. Cultura dos citros. Campinas: CATI, 1976. 100p. (CATI. Boletim técnico, 88).

CASTLE, W.S.; TUCKER, D.P.H.; KREZDORN, A.H.; YOUTSEY, C.O. Rootstocks for Florida citrus. Gainesville: University of Florida, 1993. 92p.
CUNHA SOBRINHO, A.P. da; NASCIMENTO, A.S. do; SANTOS FILHO, H.P. Instruções práticas para a cultura dos citros. Cruz das Almas: EmbrapaCNPMF, 1985. 20p. (Embrapa-CNPMF. Circular técnica, 7).

CUNHA SOBRINHO, A.P. da; SOARES FILHO, W. dos S.; PASSOS, O.P.; CALDAS, R.C. Influência de porta-enxertos na qualidade do fruto de laranjeira Baianinha sob condições tropicais. Revista Brasileira de Fruticultura, Cruz das Almas, v.14, n.3, p.99-104, 1992.

EMBRAPA. Unidade de Execução de Pesquisa de Âmbito Estadual de Rio Branco (AC). Boletim Agrometeorológico 1988 e 1989. Rio Branco, 1990. 66p. (Embrapa-UEPAE Rio Branco. Boletim Agrometeorológico, 4).

KOLLER, O.C. Citricultura: laranja, limão e tangerina. Porto Alegre: Rigel, 1994. 92p.

KOLLER, O.L.; SOPRANO, E. Porta-enxertos para Citrus limon em Santa Catarina. Pesquisa Agropecuária Brasileira, Brasília, v.27, n.3, p.523528, mar. 1992.

NEVES, E.M. Suco de laranja: guerra de gigantes. Agroanalysis, Rio de Janeiro, v.16, n.6, p.20-24, 1996.

PIO, R.M.; FIGUEIREDO, J.O. de; TEÓFILO SOBRINHO, J.; POMPEU JÚNIOR, J. Característica do fruto de oito cultivares de tangerineiras e seus híbridos. Revista Brasileira de Fruticultura, Cruz das Almas, v.15, n.1, p.43-47, 1993.

POMPEU JÚNIOR, J. Porta-enxertos para citros. In: RODRIGUES, O.; VIEGAS, F. Citricultura brasileira. Campinas: Fundação Cargill, 1980. v.1, p.279-296.

RITZINGER, R.; LEDO, A. da S.; RITZINGER, C.H.S.P.; AZEVEDO, F.F. de. Introdução e avaliação de cultivares e porta-enxertos de citros em Rio Branco-AC. Rio Branco: Embrapa-CPAF-Acre, 1992. 6p. (Embrapa-CPAF-Acre. Pesquisa em andamento, 50). 